\title{
A Case Study on Pathao: Technology Based Solution to Dhaka’s Traffic Congestion Problem
}

\author{
G. M. Wali Ullah \\ Department of Finance, School of Business, Independent University, Bangladesh (IUB) \\ Basundhara R/A, Dhaka, Bangladesh \\ E-mail: wali@iub.edu.bd
}

Ashraful Islam

BBA Program, School of Business, Independent University, Bangladesh (IUB)

Basundhara R/A, Dhaka, Bangladesh

E-mail: fishan89@gmail.com

Received: Sept. 24, $2017 \quad$ Accepted: Oct. 9, $2017 \quad$ Published: Oct. 16, 2017

doi:10.5296/csbm.v4i2.11906 URL: http://dx.doi.org/10.5296/csbm.v4i2.11906

\begin{abstract}
This case details the founding of Bangladeshi logistics and ride-sharing company Pathao, solving the traffic congestion and transportation issues of the eighth most populated city of the world, Dhaka. Founded by entrepreneurs Hussain M. Elius, Fahim Saleh and Adnan Shifat in 2015, Pathao broadly operates under two primary areas-delivery and logistics service; and, motorcycle taxi service. It has established broad operations spread throughout the country and was able to differentiate themselves from competitors using an innovative idea to tackle the traffic problem in the city and by leveraging technology to streamline its operations. The case gives an overview of logistics and transport scenario in Bangladesh through the lens of the start-up. It depicts the challenges related to starting a new company; identifying, creating and interacting with the market; securing intellectual property rights, and developing a business model in a developing country.
\end{abstract}

Keywords: Pathao, Ride-sharing, Technology, Motorcycle Taxi, Bangladesh, Start-up 


\section{Introduction}

Dhaka is the capital and economic hub of Bangladesh, one of the fastest growing economies of the world. Since winning their liberation from Pakistan back in 1971, for the first time they recorded a higher GDP per person than Pakistan in 2017. Converted into dollars at market exchange rates, it was $\$ 1,538$ in the past fiscal year (which ended on June 30th), whereas Pakistan's was about $\$ 1,470$. This remarkable turnaround has a lot to do with the blooming Bangladeshi economy, with an average 6\% growth for the last decade, and above $7 \%$ in the recent two years (Economist, 2017). While this tremendous growth brings up numerous business opportunities, it also puts a lot of stress on the limited resources of the country. With the economy shifting focus from agriculture to industrial sectors, more and more people flock to Dhaka from other parts of the country in search for jobs. According to a study by the UN population division, Dhaka was the 8th most populated city of the world, with a population of 18.2 million (Irani, 2017). It does not come as a surprise that Dhaka also has one of the most congested traffic conditions as well, with an average traffic speed of only $7 \mathrm{kmph}$ - slightly above the average walking speed (Quaium, 2017).

Pathao was founded by entrepreneurs Hussain M. Elius, Fahim Saleh and Adnan Shifat in 2015 — with the goal of tackling one of the most pressing issues plaguing businesses and commuters in Dhaka City, Transportation. There are two primary verticals of operations of the company: providing delivery and cash collection support to businesses through their Pathao Fulfillment service; and, transportation service, much like Uber but with motorbikes, through Pathao Rides. Using the same base infrastructure, Pathao serves different markets and plans on expanding operations to other delivery services, such as food delivery (Frieschlad, 2017). The trio had worked separately in their own projects, but they had identified a key problem and found a clever solution to one of the most critical problems faced by small businesses and commuters in the city. They found a nifty way to tackle the problem without having to invest huge capital. Its fleet of motorcycle drivers and bike messengers bring parcel to clients in Dhaka and beyond. The service thrives on the back of a growing demand for reliable e-commerce deliveries in Bangladesh. On the other hand, despite the lack of precedence of motorcycle taxis in the country, Pathao's Ride services caught on. In the beginning, it was a fleet of 100 drivers employed by the startup, but now they have a network of 500 freelance drivers in addition to the employed staff, serving an average three to four rides a day. Over time, Pathao hopes to expand operations to other regions of the country.

\section{Background}

Fahim Saleh, a successful entrepreneur from New York, had a vision of creating a successful venture in Bangladesh, his home soil. The intent was not only to focus on profit maximization, but help people with their services, with a stakeholder benefit oriented principle. Through Pathao, Saleh wanted to create jobs and provide employment opportunities for people. Together with Hussain M. Elius and Shifat Adnan, the chief executive officer and chief technology officer, respectively, they created Pathao which they believed had the opportunity and scope to "change the world as we know". They aimed to create a platform that will change the traditional mechanism of logistics and public transport 
in the city. Through dedication and hard work, they had been able to create a proprietary technology that sets Pathao apart from other logistics service provider in the country. Pathao's tag line "Delivery made easy" sums up the core principle of their business, which is to provide fast, secure, easy delivery services to its customers, be it E-commerce, vendors, or individual clients.

According to Elius, they wanted to make logistics as easy as sending an email. There are other courier operators in Bangladesh, all of whom are slow and inefficient, but the founders believed that they could leverage technology to bring a paradigm shift in how goods are transported (Hassan, 2016). On the other end of the spectrum, Pathao launched their Pathao Rides services in 2016, with the moto "Your Journey Our responsibility" which was able to take advantage of existing ideas and available resources to create the first ever motorcycle taxi service in the country.

\section{Why is it a Necessity in Dhaka?}

Dhaka is a sprawling urban city with its population growing in size every year at an unprecedented rate. Migration from rural areas of the country to the Dhaka has been a major contributor to the population growth. Although the growth rate has slowed down over the years compared to the 90s, the population is seemingly growing at a pace which will soon reach unsustainable levels (see Table 1). Currently the population density of Dhaka stands at 50,001 people per square mile, which is considerably larger than other major cities in Asia. According to a study by the UN population division, Dhaka was the 8th most populated city of the world, with a population of 18.2 million.

Table 1. Dhaka Population Data (Urban Area)

\begin{tabular}{|r|r|r|r|}
\hline Year & Population & Growth Rate (\%) & Growth \\
\hline 2030 & $27,374,000$ & 12.50 & $3,043,000$ \\
\hline 2025 & $24,331,000$ & 15.90 & $3,342,000$ \\
\hline 2020 & $20,989,000$ & 11.10 & $2,091,000$ \\
\hline 2017 & $18,898,000$ & 7.40 & $1,300,000$ \\
\hline 2015 & $17,598,000$ & 19.50 & $2,400,000$ \\
\hline 2010 & $14,731,000$ & 19.50 & $2,400,000$ \\
\hline 2005 & $12,331,000$ & 19.90 & $2,046,000$ \\
\hline 2000 & $10,285,000$ & 23.40 & $1,953,000$ \\
\hline 1995 & $8,332,000$ & 25.80 & $1,711,000$ \\
\hline 1990 & $6,621,000$ & 42.10 & $1,961,000$ \\
\hline
\end{tabular}

Source: Bangladesh Bureau of Statistics—Dhaka Information Statistics.

Though this growth brings numerous business opportunities, it causes tremendous strain on the resources of the city, thus driving up prices of essentials, as evident by the inflation rate of essentials in the city at 8-14\% (especially in Dhaka city) compared to the other regions of the country at 5.69\% (BBS, 2016). Moreover, the road and communication network within the city is not adequate to accommodate a large influx of traffic due to high population. There are close to 3,042,853 licensed vehicles currently operating in the country, and officials estimate about $40-50 \%$ operate in Dhaka city alone (excluding rickshaws, bicycles, and other unregistered vehicles) (BRTA, 2017). The sheer volume of vehicles in the city is a major 
barrier to business that wishes to deliver goods to its customers on time. Private vehicles are not the usual mode of transport of the average commuters in the city, due to the cost of acquisition and maintenance of the vehicles and furthermore, most vehicles are stalled on the road, making their usefulness somewhat redundant. Average commuter in the city relies on public transport, such as bus, mini-bus or "tempo" and rickshaw. It does not come as a surprise that Dhaka also has one of the most congested traffic conditions as well, with an average traffic speed of only $7 \mathrm{kmph}$ - slightly above the average walking speed.

Dhaka has earned the nickname Rickshaw capital of the world due to the largest number of rickshaws in the city. Although this medium of transport is lauded for its convenience over short distances, the fairs have seemingly become too high for people to afford and in some cases, have become a luxury. However, given the fact that it is quite unsafe and carries only a couple of people at a time, they are largely becoming an inconvenient method of transport. The best alternative to these mediums are motorbikes and bicycles. Motorbikes are easily accessible and both its acquisition and maintenance cost are somewhat palatable. As a result, an increasing number of users have been observed in the last 5 to 10 years, as per official data. Bicycles have also been on the rise largely due to its increasing consumption by the youth population. As more and more people are seeing the benefits of these vehicles, it has opened the door for businesses to take advantage of this medium to improve their logistics. Many businesses have started using bicycles instead of motor-vans to deliver smaller parcels within short distances, as it saves both time and money.

On the other hand, the smartphone penetration rate in Bangladesh was at $20 \%$ in 2015 estimated to grow even higher in the coming years as hardware is becoming cheaper, coupled with growing awareness amongst consumers about its potentials benefits, and businesses pushing for greater integration of its services through the platform. This has created a huge potential for businesses to access larger market segments seemingly inaccessible in the past. This has spurred the growth of e-commerce which last year alone has seen a growth rate of 72\% (Dailystar, 2016). This growing inconvenience in transport and delivery coupled with the expansion of app usage in the country, has allowed Pathao to incorporate the appropriate technology with the right medium of transport to get the best out of each platform to the benefit of their customers.

\section{How does Pathao Work?}

Pathao Fulfillment delivery service provides logistics support to its customers by connecting the online stores with their customers. Domestic E-commerce businesses i.e., daraz.com.bd; ajkerdeal.com etc. uses Pathao Fulfillment services to deliver the goods brought through their sites directly to the customer in person. The services offered through this vertical of business include: cash-on-delivery (COD); reverse logistics (which is a return to sender/origin support); 24-hour customer service. Consumers benefit through the added convenience of goods being delivered to their home, and businesses benefit by not having to borne huge delivery costs and offering customers a value-added service. The app uses a mobile-friendly interface which enables users to access the services on any platform: web, computer, mobile, and a 24-hour customer service means that customers can have their problems sorted at any hour of the day. Furthermore, given that the company uses motorbikes and bicycles for most of their deliveries, they have the added advantage of being more environmentally friendly 
than the competitors which somewhat reduces their carbon footprint and boosts their brand image. The various price plans offered by Patho Fulfillment services are summarized in Table 2.

Table 2. Pathao Fulfillment delivery services price plan (Prices are Bangladeshi Taka, BDT)

\begin{tabular}{|c|c|c|c|c|}
\hline Region & Timing & $\begin{array}{l}\text { Up to } \\
500 \\
\text { grams }\end{array}$ & $\begin{array}{c}\text { Between } \\
500 \mathrm{gm} \text { and } \\
1 \mathrm{~kg}\end{array}$ & $\begin{array}{l}\text { Between } \\
1 \mathrm{~kg} \text { and } 2 \\
\mathrm{~kg}\end{array}$ \\
\hline \multirow{2}{*}{$\begin{array}{l}\text { Dhaka } \\
+1 \text { COD charge on the price of the } \\
\text { product; Dhaka suburbs area includes } \\
\text { Savar, Ashulia, Keranigonj, Tongi and } \\
\text { Gazipur (within city areas) }\end{array}$} & $\begin{array}{c}\text { Standard Deliveries (24 } \\
\text { hours) }\end{array}$ & 60 & 70 & 90 \\
\hline & $\begin{array}{l}\text { Dhaka-Suburbs (48 } \\
\text { hours) }\end{array}$ & 80 & 100 & 120 \\
\hline \multirow{2}{*}{ Chittagong } & $\begin{array}{c}\text { Chittagong-Chittagong } \\
\text { ( } 24 \text { hours) }\end{array}$ & 60 & 70 & 90 \\
\hline & $\begin{array}{l}\text { Dhaka-Chittagong (72 } \\
\text { hours) }\end{array}$ & 100 & 120 & 150 \\
\hline \multirow{2}{*}{ Rajshahi } & $\begin{array}{c}\text { Rajshahi-Rajshahi (24 } \\
\text { hours) }\end{array}$ & 60 & 70 & 90 \\
\hline & $\begin{array}{c}\text { Dhaka-Rajshahi (72 } \\
\text { hours) }\end{array}$ & 100 & 120 & 150 \\
\hline \multirow{2}{*}{$\begin{array}{l}\text { Sylhet } \\
+1 \% \text { COD charge on the price of the } \\
\text { product }\end{array}$} & Sylhet-Sylhet (24 hours) & 60 & 70 & 90 \\
\hline & Dhaka-Sylhet (72 hours) & 100 & 120 & 150 \\
\hline $\begin{array}{l}\text { Nationwide } \\
\text { Conditional: no cash-on-delivery services } \\
\text { yet; the services are available through SA } \\
\text { Paribahan, Sundarban and Continental. }\end{array}$ & Nationwide-Conditional & 130 & 150 & 180 \\
\hline
\end{tabular}

Source: Pathao (official website).

Pathao Rides is a transport service provided by the business which is more like motorcycle taxi, similar to UberMoto and Go-Jek. It works through the official Pathao app available in both iOS and Android platforms. Anyone looking for a ride simply logs into the app, selects where they wish to be picked up from and where they want to be dropped. A map will appear in the app showing the location of the pick-up and drop-off point, the estimated time of arrival and the estimated fair. The interface is user-friendly and the convenience of selecting the exact location gives an added benefit to the consumer. The rates are extremely competitive and much lower than autorickshaws, plus it saves passengers a lot of time (Mahbub, 2016).

Pathao Rides charges a base fare of Tk. 25 for the first 2 kilometers and Tk. 12 for each kilometer in addition to a charge of 0.5 Tk. Per minute. Even though the rates may seem expensive at a glance, the convenience of faster travel and avoidance of traffic makes it worthwhile (Pathao, 2017). 
Table 3. Comparative pricing chart for Pathao Rides (amount in BDT)

\begin{tabular}{|l|c|c|c|c|}
\hline & Initial Fee & Cost per minute & Cost per Km & Service Fee \\
\hline Pathao Rides & 25 & 0.5 & 12 & 0 \\
\hline UberX & 40 & 3 & 18 & 0 \\
\hline Uber Premium & 80 & 3 & 22 & 0 \\
\hline Toma Taxi Cab & 85 & 4.25 & $34($ after $2 \mathrm{~km})$ & 20 \\
\hline
\end{tabular}

Source: Official websites of Toma Group, Uber Estimate and Pathao Rides.

As seen in Table 3, Pathao Rides fares are more competitive with their prices compared to the other ride-sharing and taxi services. Even though Pathao Rides are for a single user, the cost per person is still justified because of the convenience of faster travel and cheaper rate compared to other offerings in the market place. This point was solidified with the fact the Pathao was able to obtain repeat customers without expensive promotional offers. Uber continuously provides discount offers to retain their customers, and has a lot of controversial cases arising from their contracted drivers of their fleet. On the other hand, there have been very few instances of public customer constraints from Pathao Rides drivers.

As one of the customers pointed out, while the fare of Pathao may seem expensive at first glance, it seems rather reasonable while considering how the competitors would cost. While traditional taxi cab services can seat a maximum of 3-4 persons in one seating, Pathao can only take one customer per bike. In such case, dividing the total fare using these taxi services between all the passengers would make it much cheaper compared to Pathao. However, majority of the time most customers avail the service alone, not finding people with common destinations to share the ride with. In that situation, the lone customer has to bear the total cost by him/herself. Rather than bearing the full cost and being stuck in the Dhaka traffic with a four-wheeled taxi/car, it seems more reasonable to pay the lesser shared amount of fare with a motorbike that would make the travelling much faster and efficient. That is one of the primary factor behind Pathao's success among the Dhaka's traffic stuck population using their service almost daily.

\section{How did they Raise the Funds?}

Pathao was able to raise funding for its business through seed investment of undisclosed amount through local and foreign investors and friends and family. It had a small operation in the beginning but they were able to expand organically. They are however, looking for venture capital funds to scale-up their business and offer more value-added service to their clients. It is able to meet its short-term financing needs for working capital financing through the cash-flow generated by the business, but they are facing problem in sourcing long-term financing for the expansion of the business, mainly due to the fact that there is little to no successful tech start-ups in the country so-far. Also, traditional financial institutions i.e. banks and NBFIs consider such tech start-ups with no precedence to be risky, and thus do not fund these projects at the initial level. However, the CEO is confident that a proven track record and healthy growth will enable them to acquire funds through institutions (Frieschlad, 2017).

\section{Customer Experiences Using Pathao}

Over the course, Pathao has been lauded for its super-friendly service and ease of use. They 
have been very prompt at ratifying any issues the users experienced, in particular with the mobile app. specifically, university students and office goers are the primary users of the service. Most of these users when asked, were extremely positive with their experience. One customer, Mr. Pavel Anik, a postgraduate student was ecstatic at how Pathao saves time and makes it possible for him to attend his classes after his work ends at 7PM. After his work, he has to rush Gulshan-1 to Basundhara R/A for his classes, through the rush hour traffic. While any other taxi service takes around 1 hours and 30 minutes to reach the destination, with Pathao he can attend his classes within 30 minutes. Before Pathao was available, he often used to miss a larger portion of his evening MBA lectures-resulting in poor results. Now that he can regularly attend classes and work properly at the same time, he attributes a lot of this peaceful schedule to Pathao.

Similarly, university lecturer Mr. Anwar Zahid also thinks that, Pathao has made his daily commute to the distant corner of Dhaka city to his workplace much easier. Normally, he used to ride a bus and go through a hellish 3 hour journey to his work every day. Due to his family business in Old Dhaka, he cannot move over to any other parts of the city which would be close to his office. It resulted in poor work life balance and family issues, which severely harmed his functioning capacity. Now with Pathao, he can make the commute in less than half the time than before. With motorbikes, it is much easier to travel through the traffic jam and avoid being stuck in bottlenecks.

However, one common drawback almost all the users interviewed mentioned was, the lack of extra helmets for the passenger in some of the driver's vehicle. Especially, during the rainy season, passengers are not provided with raincoat or any other accessory to cope with the drizzling rain while riding the bikes. Almost all the users suggested some sort of accessory to be provided during the rainy season, as without it most of the prospective customers are unable to use Pathao at that time. Also, it can be troubling for the customers to travel using Pathao amidst the dust and polluted air and sound of the city roads. Air pollution driven by coarse particulate matter has grown so severe, that it is blamed by crisis resolution NGO IRIN for premature deaths for 15,000 people in the 14.5 million-person city (IRIN, 2009). Moreover, Boston-based Health Effects Institute (HEI) also mentioned Bangladesh as being second in a global list of cities with worst air pollution (HEI, 2017). Thereby, even though Pathao solves a lot of the traffic problem of Dhaka, it does so without taking any additional steps that could help its customers dealing with the environment. One customer did recommend the organization in supplying its contracted drivers with masks to help dealing with the polluted air, something the organization should look into.

\section{Major Challenges of Operating in Bangladesh}

One of the major challenges faced by Pathao initially was gaining the trust of the businesses and consumers. The idea behind the service was simple and convenient but being a new entrant into the market, its customers were rightly skeptical. Through numerous brand awareness campaigns, like "Free Experience Campaign: My First Pathao Ride”, the business was able to garner and build much needed trust. They have extensive number of clientele and more customers are starting to use their services.

Other challenges that the business faces include, poor communication infrastructure in many regions where they operate. Inadequate road network, improper lane system and even 
uncooperative traffic enforcers continuously cause the business additional resources and money. Even coordination and communication between many of its partners and clients have been made difficult by shoddy communication networks. Since, the business is spread out across multiple locations throughout the country; communication between the teams is becoming more and more challenging.

Due to the absence of any legal framework for the type of motorcycle taxi services in the country, the riders continuously face problems with the local law enforcements, causing delays and most cases cancellations by passengers. Drivers of Pathao do not wear any identification tags or logo in their bikes, as they are yet to receive government approval. Absence of these identifications sometime also causes problem for customers in finding their drivers, especially for those who lack the technical know-how of using the app. However, the growing popularity and brand awareness has compelled the authorities to start drafting proper laws and legal framework to accommodate such businesses in the country.

One particular issue has been the almost non-existent female users of this service in Bangladesh. Despite major strides made in female empowerment in the country, norms and religious issues still somewhat restricts the female population of this part of the world from publicly sharing motorcycles with male drivers who are not their legal guardians and spouses. While things have started changing with the rising education coverage throughout the country, there have been very few female passengers and almost zero drivers using Pathao rides service in Dhaka.

The last and the most difficult challenge is ensuring safety and security for both the packages that are delivered and the passengers that are ferried to various locations. Motorcycles are in general subject to numerous accidents in the city. Due to lackluster regulations of traffic laws and lack of awareness of the pedestrians and other vehicles, accidents are commonplace in the city and Pathao is continuously trying to ensure that no such incidents are reported against their service. They make sure the deliveries are made on time and in proper condition and the passengers wear helmets even if they insist against it.

\section{The Future}

Pathao is a start-up that is constantly evolving and the team believes in embracing dynamism which is etched into their business philosophy. The company's founders hope to expand their network to include the whole of Bangladesh and ensure that everyone gets the opportunity to reap the benefits they provide. It is part of the digitalization movement that has taken the world by storm. While the electronic realm in Bangladesh is not on par with the globe, however it is growing rapidly. E-commerce is the future of the economy, and Pathao will play an integral part in its technological advancement. With the lack of competition in the motorcycle taxi service, high price of other tech based taxi services i.e., Uber and global criticisms of many of the international services open up big opportunities for Pathao to capitalize on in the long run.

\section{References}

BBS. (2016). Price and Wages (CPI, QIIP). [Online] Available:

http://www.bbs.gov.bd/site/page/29b379ff-7bac-41d9-b321-e41929bab4a1/CPI-and-QIIP 


\section{Macrothink \\ Case Studies in Business and Management \\ ISSN 2333-3324 \\ 2017, Vol. 4, No. 2}

BRTA. (2017). Registered Motor Vehicle Statistics. [Online] Available:

http://www.brta.gov.bd/newsite/en/dhaka-metro-up-to-june-2016/

Dailystar. (2016). Bangladesh to see 72 pc growth in e-commerce sales. The Daily Star.

Economist. (2017). Bangaldesh’s GDP per person is now higher than Pakistan's. The Economist.

Frieschlad, N. (2017). Meet the fast-growing Go-Jek of Bangladesh. Techniasia.

Hassan, N. A. (2016). Ready, set, done. Dhaka Tribune.

HEI. (2017). State of Global Air 2017. Retrieved from USA.

Irani, B. (2017). Population growth kept at bay despite flagging initiatives. Dhaka Tribune.

IRIN. (2009). Air pollution choking Dhaka. [Online] Available:

http://www.irinnews.org/report/83772/bangladesh-air-pollution-choking-dhaka

Islam, M. Z. (2015). Smartphone penetration to reach 20pc by this year. The Daily Star.

Retrieved from The Daily Star.

Mahbub, S. (2016). Beat Traffic with Pathao. Hifi Public.

Pathao. (2017). Pathao. [Online] Available: https://pathao.com/

Quaium, R. (2017). Wheels in motion. Dhaka Tribune.

\section{Copyright Disclaimer}

Copyright for this article is retained by the author(s), with first publication rights granted to the journal.

This is an open-access article distributed under the terms and conditions of the Creative Commons Attribution license (http://creativecommons.org/licenses/by/3.0/). 